\title{
Levando a Cozinha Hospitalar ao Paciente: uma Estratégia para Sensibilizar Funcionários e Conquistar Pacientes.
}

\author{
Cardoso, Elisabeth; Habiro, Renata Sayuri; Isosaki, Mitsue \\ Serviço de Nutrição e Dietética do Instituto do Coração do HCFMUSP — nutbeth@incor.usp.br
}

Introdução: o trabalho em uma cozinha hospitalar tem como característica a prestação diária, ininterrupta e contínua do atendimento aos pacientes e as atividades neles desenvolvidas exigem exatidão, rapidez e sincronia da equipe. Além disso, dependendo da função e do local de trabalho, os seus trabalhadores são submetidos à condições como ruído, calor, umidade, risco de acidentes, esforço físico e mental, ritmo de trabalho intenso, monótono e repetitivo. o atendimento à individualidade dos pacientes, respeitando os seus hábitos e outras questões culturais, mesmo diante da necessidade de restrições dietéticas severas, demanda grande esforço por parte dos funcionários da cozinha hospitalar. Desta forma, a alimentação pode ser um item de insatisfação durante a permanência na unidade hospitalar podendo ser agravada se o paciente não se sentir ouvido e compreendido. para aqueles que trabalham diretamente na produção de refeições o distanciamento do cliente final pode criar a sensação de não valorização de um trabalho tão desgastante. em um hospital vinculado à rede do Sistema Único de Saúde (SUS) especializado em Cardiologia e Pneumologia, observou-se que alguns pacientes submetidos a longos períodos de internação e com necessidades alimentares especiais e que demandavam grande empenho da equipe de produção de refeições, muitas vezes manifestavam o desejo de conhecer os profissionais que preparavam suas refeições. Desta forma, percebeu-se que a criação de um canal de relacionamento entre os profissionais de cozinha e os pacientes poderia repercutir na qualidade do serviço prestado e na melhoria da satisfação do cliente. Objetivo: com o objetivo de melhorar o serviço prestado aos pacientes internados, foi criado um programa de sensibilização dos profissionais que atuam na cozinha de um Serviço de Nutrição Hospitalar, promovendo visitas destes profissionais às unidades de internação. Método: As visitas ocorrem periodicamente, sendo que os profissionais da cozinha são levados pelo nutricionista a conhecer os pacientes nas unidades de internação. São selecionados pacientes com histórico de internação prolongada e/ou necessidades especiais no que se refere à alimentação, ou ainda que manifestem o desejo de conhecer os responsáveis pelo preparo das refeições. Resultados: como resultado observou-se melhora no desempenho dos servidores que passaram a se sentir mais motivados e valorizados, pois passaram a perceber a importância de seu trabalho junto à recuperação do paciente e a gratidão destes ao resultado de seu trabalho. em acréscimo, os pacientes se sentiram mais acolhidos conhecendo os personagens responsáveis pela sua alimentação. Conclusão: Simples ações podem resultar em grandes ganhos no que se refere à melhoria das relações interpessoais de profissionais que não atuam em contato direto com pacientes, e cujo resultado do trabalho pode impactar sobremaneira na satisfação dos pacientes e, consequentemente, em sua recuperação. Assim, a partir da realização do programa desenvolvido pelo serviço de Nutrição torna-se clara a viabilidade para concretizar propostas simples de atendimento aos pacientes da rede SUS sem a necessidade de recursos financeiros elevados.

Cardoso, Elisabeth; Habiro, Renata Sayuri; Isosaki, Mitsue. Levando a Cozinha Hospitalar ao Paciente: uma Estratégia para Sensibilizar Funcionários e Conquistar Pacientes.. In: Anais do Congresso Internacional de Humanidades \& Humanização em Saúde [= Blucher Medical Proceedings, num.2, vol.1]. São Paulo: Editora Blucher, 2014. ISSN 2357-7282

DOI 10.5151/medpro-cihhs-10186 